\title{
Aplastic anemia in systemic lupus erythematosus: $A$ better prognosis acquired aplastic anemia
}

\author{
Pannu $\mathrm{AK}^{1 *}$, Varma $\mathrm{SC}^{1}$ \\ ${ }^{1}$ Department of Internal Medicine, Post Graduate Institute of Medical Education and Research, Chandigarh, India
}

Received: 25 November, 2016; Accepted: 14 December, 2016; Published: 20 December, 2016

*Corresponding author: Ashok kumar Pannu, Department of Internal Medicine, Post Graduate Institute of Medical Education and Research, Chandigarh, India, Tel no: +919914291115; E-mail: gawaribacchi@gmail.com

\section{Introduction}

Aplastic anemia (AA) is an uncommon hematologic manifestation of systemic Lupus erythematosus (SLE) with significant difference in the course and outcome from other forms of acquired AA due to underlying immune mediated mechanism of the disease. Here we report a case of SLE with thrombocytopenia at presentation and later evolved to develop pancytopenia with bone marrow aplasia.

\section{Case report}

A 58 year old lady was admitted to this hospital because of gum bleeding and low grade fever for 2 years with a history of recurrent oral ulcers, alopecia and Raynaud's phenomenon.

In 2014, she was evaluated in another hospital and found to have thrombocytopenia (platelet count $70 \times 10^{9} /$ l) with positive antinuclear antibodies (ANA), anti-Ro (SS-A) and anti-RNP. A diagnosis of SLE was made according to ACR Classification criteria for SLE. ${ }^{[1]}$ She was started on oral prednisone, however six months later her platelet counts started falling. On investigation complement levels (C3 \& C4) were low. Bone marrow (BM) aspiration and biopsy was done which showed normoblastic erythroid hyperplasia. A three days pulse methyl-prednisolone 1 $\mathrm{g} /$ day followed by prednisolone $50 \mathrm{mg}$ OD was started. However patient again developed thrombocytopenia when prednisolone was started tapering. This time oral eltrombopag $50 \mathrm{mg}$ OD was added which was later stopped in 2015 with improvement in platelets.

In May 2016, she developed pancytopenia for which steroid dose was increased. She was transfused 3 unit packed red blood cells (PRBC) and 3 units random donor platelets (RDPs) and the dose of prednisolone was increased.

She came to this hospital with pallor, gum bleeding and low grade fever. On examination she had fundal hemorrhages. A complete blood count showed hemoglobin (Hb) $4.0 \mathrm{~g} / \mathrm{dl}$, total leucocyte counts (TLC) $1.2 \times 10^{9} / 1$ with absolute neutrophil counts (ANC) of 324 and platelets $4 \times 10^{9} / \mathrm{l}$. A corrected reticulocyte count was 0.46 and direct coomb's test was negative, a repeat ANA was $2+$ with speckled pattern and anti-Sm was positive. A BM aspiration and trephine was repeated which was hypocellular and consistent with aplastic anemia. paroxysmal nocturnal hemoglobinuria (PNH) was excluded by absence of PNH clones. HIV serology and polymerase chain reaction for CMV were negative.

Patient was transfused 4 units PRBC and 12 units of RDP, and was started on prednisolone $50 \mathrm{mg}$ OD along with danazol 200 mg BD, however cytopenias did not improve. A three days of pulse methyl-prednisone $1 \mathrm{~g}$ /day was tried without any subsequent benefit. Finally she was started on oral cyclosporine $100 \mathrm{mg} \mathrm{BD}$ following which all three cell lineage started improving. At the time of discharge, Hb was $9.0 \mathrm{~g} / \mathrm{dl}$, TLC 3200 with ANC of 1344 and platelets 24,000 .

\section{Discussion}

Hematological involvement is common in SLE and is often presenting manifestation of the disease. Hematological disorder is included in the SLICCC (Systemic Lupus International Collaborating Clinic) criteria for classification for SLE. This includes haemolytic anaemia or leucopenia $\left(<4.0 \times 10^{9} / \mathrm{l}\right)$ or lymphopenia $\left(<1.0 \times 10^{9} / \mathrm{l}\right)$ or thrombocytopenia $\left(<100 \times 10^{9} /\right.$ l). [2]

The most frequent hematologic manifestation of SLE is anemia, usually normochromic normocytic, reflecting chronic illness. Aplastic anemia, however, is rarely reported, but in many cases, the role of concomitant drug therapy and secondary infections is confounding. BM examination is essential in cases of pancytopenia, particularly if the patient is receiving myelotoxic therapy such as azathioprine, mycophenolate mofetil or cyclosphosphamide. Specific features may present in the marrow to suggest drug-induced myelotoxicity. Azathioprine, for example, may cause aplastic anaemia, erythroid hypoplasia and megaloblastic changes. BM examination may also reveal hematological malignancy and hemophagocytosis.

Common abnormalities in the BM in patients with SLE include increased haemopoietic precursors suggestive of peripheral destruction or alternatively SLE induced hypocellularity, an increase in reticulin and a plasmacytosis. ${ }^{[3,4]}$ 
BM necrosis with stromal alterations is also frequently seen. Voulgarelis $\mathrm{M}$ et al. reported the BM findings of 40 patients with SLE and unexplained cytopenias: hypocellularity, necrosis, and stromal changes such as edema and fibrosis along with vascular changes were frequently present. BM was hypocellular in $58 \%$ of patients, normocellular in $17 \%$, and hypercellular in $25 \%{ }^{[5]}$

The mechanism of hematopoietic failure in SLE is immunemediated. Autoantibodies, both complement dependent or independent were found to suppress both erythroid- and granulocytic-colony formation by hematopoietic Colony-Forming Units (CFU). ${ }^{[6-9]}$ Autoreactive $\mathrm{T}$ cells were shown to inhibit CFU formation, damage hematopoietic stem cells through direct cytotoxic destruction, or induce apoptosis. ${ }^{[10]}$

Regarding the treatment of cytopenias, a detailed drug history and work up for seconday infection and hemophagocytic syndrome is essential. Immunosuppressive therapy is the cornerstone of the management of disease related BM failure. Systemic corticosteroid (oral prednisolone or pulse methylprednisolone) alone caused recovery in some cases, however most cases required further immune suppression. ${ }^{[11,12]}$

The use of plasmapheresis has been used successfully, aiming to remove auto-antibodies to BM hematopoietic precursors. ${ }^{[13-16]} \mathrm{A}$ dramatic response was seen after intravenous cyclophosphamide $(0.5-1.0 \mathrm{gm} / \mathrm{m} 2)$, usually one or two pulse therapy was sufficient ${ }^{[17-19]}$ Supportive measures like transfusion of red cells and platelets, use of granulocyte colony stimulating factor and broad-spectrum antibiotics are an important part of management of aplastic anemia.

Reported cases of SLE associated BM aplasia showed better outcome than idiopathic acquired aplastic anemia which often has a poor outcome with a significant number of patients remains transfusion dependent and requires hematopoetic stem cell transplantation. This reflects the significant difference in the pathogenesis of the disease.

\section{Conclusion}

BM examination is utmost important in all cases of SLE with pancytopenia, severe or persistent leucopenia or thrombocytopenia. Conversely, in all cases of aplastic anemia, one should always look for clinical features of SLE and work up accordingly. Adequate immunosuppressive therapy can do wonder in this form of acquired BM aplasia.

\section{References}

1. Tan EM, Cohen AS, Fries JF, Masi AT, McShane DJ, Rothfield NF, et al. The 1982 revised criteria for the classification of systemic lupus erythematosus. Arthritis Rheum. 1982;25(11):1271-1277.

2. Petri M, Orbai AM, Alarco'n GS, Caroline Gordon, Joan T. Merrill,Paul R. Fortin, et al. Systemic Lupus International Collaborating Clinics Classification Criteria for Systemic Lupus Erythematosus. Arthritis Rheum 2012; 64(8):2677-2686. doi: 10.1002/art.34473.

3. Feng CS, Ng MH, Szeto RS, Li EK. Bone marrow findings in lupus patients with pancytopenia. Pathology 1991; 23(1):5-7.
4. Pereira RM, Velloso ER, Menezes Y, Gualandro S, Vassalo J, Yoshinari. Bone marrow findings in systemic lupus erythematosus patients with peripheral cytopenias. Clin Rheumatol 1998;17(3):219-222.

5. Voulgarelis M, Giannouli S, Tasidou A, Anagnostou D, Ziakas PD, Tzioufas AG. Bone marrow histological findings in systemic lupus erythematosus with hematologic abnormalities: a clinicopathological study. Am J Hematol 2006;81(8):590-597. doi:10.1002/ajh.20593.

6. Brooks BJ Jr, Broxmeyer HE, Bryan CF, Leech SH. Serum inhibitor in systemic lupus erythematosus associated with aplastic anemia. Arch Intern Med 1984;144(7):1474-1477.

7. Bailey FA, Lilly M, Bertoli LF, Ball GV. An antibody that inhibits in vitro bone marrow proliferation in a patient with systemic lupus erythematosus and aplastic anemia. Arthritis Rheum 1989;32(7):901905.

8. Liu H, Ozaki K, Matsuzaki Y, Abe M, Kosaka M, Saito S. Suppression of haematopoiesis by IgG autoantibodies from patients with systemic erythematosus (SLE). Clin Exp Immunol. 1995;100(3):480-485.

9. Fitchen JJ, Cline MJ, Saxon A, Golde DW. Serum inhibitors of hematopoiesis in a patient with aplastic anemia and systemic lupus erythematosus. Recovery after exchange plasmapheresis. Am J Med. 1979;66(3):537-542.

10.Giannouli S, Voulgarelis M, Ziakas PD, Tzioufas AG. Anaemia in systemic lupus erythematosus: from pathophysiology to clinical assessment. Ann Rheum Dis. 2006;65(2):144-148.

11. Wolach B, Choc L, Pomeranz A, Ben Ari Y, Douer D, Metzker A. Aplastic anemia in neonatal lupus erythematosus. Am J Dis Child. 1993;147(9):941-9444.

12. Chute JP, Hoffmeister K, Cotelingam J, Davis TA, Frame JN, Jamieson T. Aplastic anemia as the sole presentation of systemic lupus erythematosus. Am J Hematol. 1996;51(3):237-239. doi: 10.1002/ (SICI)1096-8652(199603)51:3<237.

13. Abdou NI, Lindsley HB, Pollock A, Stechschulte DJ, Wood G. Plasmapheresis in active systemic lupus erythematosus: effects on clinical, serum, and cellular abnormalities. Case report. Clin Immunol Immunopathol. 1981;19(1):44-54.

14. Bailey FA, Lilly M, Bertoli LF, Ball GV. An antibody that inhibits in vitro bone marrow proliferation in a patient with systemic lupus erythematosus and aplastic anemia. Arthritis Rheum. 1989;32(7):901905.

15. Marques JA, Rhim H, Distenfeld A. Inhibition of hematopoiesis by a plasma factor in a case of aplastic anemia associated with systemic lupus erythematosus. P R Health Sci J. 1995;14(4): 293-296.

16. Fitchen JJ, Cline MJ, Saxon A, Golde DW. Serum inhibitors of hematopoiesis in a patient with aplastic anemia and systemic lupus erythematosus. Recovery after exchange plasmapheresis. Am J Med 1979; 66(3): 537-42.

17. Walport MJ, Hubbard WN, Hughes GR. Reversal of aplastic anaemia secondary to systemic lupus erythematosus by high-dose intravenous cyclophosphamide. Br Med J (Clin Res Ed). 1982;285(6344):769-770.

18. Roffe C, Cahill MR, Samanta A, Bricknell S, Durrant ST. Aplastic anaemia in systemic lupus erythematosus: a cellular immune mechanism? Br J Rheumatol. 1991;30(4):301-304.

19. Winkler A, Jackson RW, Kay DS, Mitchell E, Carmignani S, Sharp GC. High dose intravenous cyclophosphamide treatment of systemic lupus erythematosus associated aplastic anemia. Arthritis Rheum. 1988;31(5:693-694. 